\title{
Register Variation in Electronic Business Correspondence
}

\author{
RosA GIMÉNEZ-MORENO \\ Universidad de Valencia
}

Received: 10 December 2010 / Accepted: 29 December 2010

\begin{abstract}
Electronic correspondence is a highly dynamic genre within the business world in which Register Variation (RV) is frequently used as a tool to improve communication but it often can lead to misunderstanding. In order to shed some light on this still unexplored area, the present study firstly offers a practical approach to classify and analyse RV within professional communication. After this, it reviews previous studies on email writing to apply their findings to this approach and, in the third part of the study, a corpus of recent business emails in English is analysed to examine how the key parameters of RV are currently used within this genre. The results will show that, not only the context, but also the roles and intentions of the senders influence an email's register, often causing internal oscillations between different registers within the same text.
\end{abstract}

\section{KEYWORDS:}

Email, register variation, business English, corpus analysis, electronic correspondence.

\section{RESUMEN}

La correspondencia electrónica es un género comunicativo de especial dinamismo dentro del mundo empresarial en el que la variación de registros se utiliza como herramienta para mejorar la interacción y las relaciones entre los interlocutores, pero que a menudo también genera confusión y malentendidos. Para aportar luz a esta área, el presente trabajo ofrece una aproximación práctica para la clasificación y el análisis de los registros linguiísticos dentro de la comunicación profesional. A continuación, revisa los estudios previos sobre este género con el fin de adaptar sus resultados a la teoría propuesta. Finalmente, se analiza un corpus de mensajes escritos en inglés para examinar el funcionamiento de los registros dentro de este género. Los resultados mostrarán que, no solo el contexto situacional, sino sobre todo los roles e intenciones de los emisores determinan el registro de un mensaje, provocando a menudo oscilación interna entre varios registros dentro del mismo texto.

PALABRAS CLAVE:

Email, Registro Lingüístico, Inglés Empresarial, Análisis de Corpus, Correspondencia Electrónica.

\footnotetext{
*Address for correspondence: Rosa Giménez Moreno. Universitat de València-IULMA. Facultat d'Economia, Avda dels Tarongers, s/n 46021, Valencia, Spain. Tel: 0034 963828429; Fax: 0034 961625429; Email: rosa.Giménez@uv.es
} 


\section{INTRODUCTION}

As Danet (2001) states, in the last 20 years electronic mails have become the most widespread and frequent means of written communication. Although at the beginning this genre shared most of the characteristics of written formal correspondence (i.e. Hawisher \& Moran, 1993), in recent years it has been increasingly moving towards other more informal forms of instant communication, such as mobile text messaging (SMS). In order to warn against the overuse and misuse of templates, shortenings, colloquialisms and other forms of free and fast language, many specialists inside the business world are emphasizing the importance of writing correct emails, following adequate etiquette rules to avoid damaging professional image and liability risk.

As previous studies have already indicated, this genre has its own discourse peculiarities (i.e. Baron, 2000); however, the capacity of writing correct texts also depends on other important parameters such as the role of the participants and the contextual factors surrounding the action of writing that particular message. These are two basic parameters which define the concept of communicative register (Giménez Moreno, 2006). Therefore, to a certain extent, the mastering of electronic business correspondence is dependent on the user's capacity to identify how registers vary inside this genre and how to use the most appropriate register criteria in each situation. An informal email addressed to a close friend does not follow the same criteria as an informal email addressed to a colleague. Formality and informality are two concepts which are very helpful when identifying Register Variation (RV) but they are also very relative and might be misleading when applied to specific settings and discourse types, especially within professional communication.

With the aim of casting some light on this scarcely studied field, the first part of the present work will be dedicated to defining the main criteria which differentiate RV in professional settings. After this, in the second part, previous studies on electronic correspondence will be revised to extract the main features of this genre that can influence RV from the approach proposed in the first section. From this same perspective, in the third part, a corpus of recent business emails written by native business professionals will be analysed in order to identify the key parameters of RV within this genre from the native users' perspective. The last sections will comment on the results of the study and will provide some recommendations for Business English practitioners on how to develop RV awareness and improve electronic correspondence writing skills.

\section{REGISTER VARIATION IN PROFESSIONAL SETTINGS}

In the past 40 years, within the world of Applied Linguistics, and in other areas concerned with social and professional communication, many experts have used the word register to imply different concepts and have expressed the concept of register using different terms. The 
result is that now there seems to be certain confusion between registers and other parameters of linguistic variation, such as communicative modes (e.g. written or sign language register), genres (e.g. the register of letters), styles (e.g. creative register) and idiolects (e.g. the register of a famous politician or broadcaster). There are also studies which identify registers with functions and other grammatical features (e.g. the register of humour or the register of impersonal discourse), topics (e.g. the register of sports) and with disciplines (e.g. the register of economics or law). Most of these studies relate the notion of register to the scale of formality as its key defining parameter (Giménez Moreno, 2006). As stated in Giménez Moreno (1997) a simple distinction among genres, registers and styles - the three most conflicting concepts - is that genres follow procedural and functional parameters, registers depend on the roles and contexts, and style variation changes according to the users' personal linguistic and communicative choices, often driven by individual peculiarities and fashion trends. Ruíz Garrido (2010: 84) points out that these terms and concepts are different but complementary ways of looking at discourse, since registers can be seen as a kind of internal variation of genres and vice versa, both always becoming personalised in daily life depending on the communicator's chosen style. However, the utility of the concept of register will not be fully developed until experts cast more light into its still indistinct definition and sort out the complexities of its systematic application to all levels of everyday communication. RV, as a line of research, has already been explored by pioneering specialists such as Gregory and Carroll (1978), Halliday (1978, 1980), Ghadessy (1988) and Biber (1995), among others.

The most famous and generally accepted approach to explain the concept of register was provided by Halliday (1978). He defines language registers based on the three wellknown parameters: field (what is happening or activities involved), tenor (participants' status and roles) and mode (type of language and communication channels). His systemic functional perspective has promoted many studies which research linguistic and communicative features associated to a few differentiated registers, mainly professional registers (e.g. Ghadessy, 1988). Yet it is a theoretical approach which does not seem to help to establish a practical and clear division between registers and other close types of variation, these frameworks being very difficult to apply to all registers systematically. As reviewed in Giménez Moreno (1997 and 2006), the same difficulties are found in approaches offered by other great experts in this field such as Biber's multidimensional (MD) method of register analysis (Biber, 1995).

A rather basic but effective way to understand this distinctive nature of academic registers was proposed in Giménez Moreno (2006), based mainly on native speakers' comments about their use of language variation and her teaching experience. Like most previous studies, this approach also considers registers as verbal repertoires which depend on the specific language and community conventions (contextual, social and cultural), not so much on individual habits and choices (clearly differentiating registers also from idiolects and styles). However, from this perspective these verbal repertoires are seen as groups of communicative features which move up and down in our daily lives depending on their 
situation within a scale swinging from the most intimate and informal parameters of human communication to the most ritual and formal ones. It is therefore very difficult to isolate, define and analyse one specific verbal repertoire from the other neighboring registers in that continuum. What seems clear is the existence of both limits: an intimate register used in informal personal life situations, and a ritual register appropriate in formal public life situations. It is also apparent that communication in our personal life not only has an informal version (e.g. a love encounter), but also a more formal one (e.g. a discussion with a friend); and communication in our public life not only has a formal version (e.g. award ceremony), but also a more informal/casual one (e.g. an encounter with a neighbour or an acquaintance). This linguistic variation tells us that registers not only vary according to the communicative settings, but also according to the particular roles of the participants. These roles fluctuate in our daily communication depending, firstly, on the discourse and epistemological communities we belong to in both our personal and public/professional lives (Alcaraz Varó, 2007:4; Yus, 2010:42), and secondly on our particular intentions: if two colleagues intend to become friends they might use personal discourse strategies to introduce each other to their amicable epistemological communities. Taking into account these two parameters - context and roles - in our private life at least two macro-registers are distinguishable: (1) a family one, used with relatives, and (2) an amicable one, used with friends. In the same vein, in our public life at least two other macro-registers can be differentiated: (3) a social one, used with neighbours and other citizens in social open settings, and (4) a professional one, used with colleagues and other professionals in institutional and work settings (Giménez Moreno, 2006:100).

Nonetheless, if we observe our everyday communication, each of these four macroregisters also has its own internal fluctuation between its more formal/ritual pole and its casual/informal version. For example, if two neighbours meet for the first time while walking their dogs their conversation will tend to spin around a social-formal register, but if they know each other and have got on well for 20 years their chat will be on a social-informal level. This level of informality will differ from that used in the informal intimate register, for example between two lovers chatting in a relaxed manner (which will also contrast with its formal version, for example, when relatives are having their lunch on Christmas day). Therefore, it can be said that each of these four registers, or macro-registers, can be expressed in at least three versions, tones, frequencies or levels: (1) a more relaxed, flexible or informal, (2) a neutral, conventional or standard, and (3) a more distant, rigid or formal.

As a sample, we asked native speakers (10 informants collaborating in our study, see section 4) to differentiate among registers within professional email writing by classifying 4 sets of 3 examples of each level such as the example below. The informants labelled, almost instinctively, each example according to each level of variation.

Level/Tone 1: Last night I attended the launch of the new furniture collection by John Stevens. The products are very well made and the event was a success. [Formal] 
Level/Tone 2: I went to the launch of John's new products. It was a good event and the range will be profitable. [Neutral]

Level/Tone 3: Went to the launch last night. Great products, ace do! Chairs were a bit uncomfy but he'll make some dosh out of it. [Casual]

This natural perception about RV that native speakers develop during their growth and education is very difficult for non-native speakers to learn. Most of the references cited so far in this section include lexical and grammatical features which traditionally have been attached to both extremes of professional discourse and which have proved to be very useful for students of Business English. The following ten correlations summarise the most important linguistic features which vary in order to make professional communication more informal/casual (column A) or more formal/ritual (column B).

\section{A $\quad$ B}

(+) INFORMAL/CASUAL

(Showing commitment, involvement and closeness)

1. Personal expressions

2. Active verbs/expressions

3. Direct speech

4. Ordinary reporting verbs (e.g. say)

5. Ordinary connectors (e.g. so)

6. General terms/expressions (e.g. man)

7. Emotive/subjective/attitudinal terms (e.g. guess)

8. Phrasal verbs and informal idiomatic expressions

9. Use of contractions, abbreviations and "fast language"

10. Straight statements and direct commands
(+) FORMAL/RITUAL

(Showing deference, neutrality and objectivity)

1. Impersonal expressions

2. Passive verbs/expressions

3. Indirect speech

4. Specific reporting verbs (e.g. mention)

5. More elaborate connectors (e.g. furthermore)

6. Precise terms/expressions (e.g. technician)

7. Neutral/objective terms (e.g. inform)

8. Latin terms and standard formal expressions

9. Detailed and concrete expressions without contractions using nominalization and modifiers

10. Politeness, caution and mitigation markers

Table 1. 10 linguistic parameters of RV in professional communication (Adapted from Giménez Moreno, 2010:302).

If these linguistic parameters are applied to the genre of email writing the result might be two very different versions of the same message. The following fragment is the first half of an email sent by a student to his lecturer asking for classroom acceptance (from Giménez Moreno, 2010:303). As it is written in a casual tone the numbers in brackets correspond to the related parameters from column A:

Hi Paul (8-9)

How's (9) it going? (3) It's (3) a while (6) since we bumped into (8) each other downstairs (6). Since I (1) last saw (6) you I've (9) past all my exams (9) and (5) I'm off (8-9) to the Big Apple (8) next term for a spell of work experience (8), which is fantastic! (7-10) Can I ask you a favour related to this? (3) 
I was in the faculty yesterday and (5) they (6) told me (4) that your course was full. God, you're popular! (7-10) And (5) it's (9) only just (8) the start of registration! (7-10) Mind you (1-8) I'm not surprised (8-9). Anyway (5-8) I got chatting (8) to one of the ladies (6) in admin (9) who was sorting out (8) all the people (6) on the courses, and (5) she said (5), "You've got (9) no chance (8) unless you talk to the tutor direct" - which is why I'm (9) dropping you a line (8).

$[\ldots]$

As the email shows, the sender's main role is to perform as a student, this is why the professional register acts as the main pole of variation in its casual version, but he also wants to show his lecturer that he is open to a more social relationship, addressing him as he would with an acquaintance (expressed with direct questions such as "How's it going?" or conversational expressions such as: "Mind you" or "Anyway"). In the same way, in certain stages he tries to demonstrate camaraderie, close to companionship, using a friendly salutation such as "Hi Paul" and expressions which belong to an amicable register, for example: "God, you are popular!" or "I'm dropping you a line". This oscillation throughout the formality continuum is a connatural feature of register use: the simplicity or complexity when modulating a register will depend upon the simplicity or complexity of the roles the interlocutors play regarding their intentions and how they perceive their situational context. Also we have to bear in mind that some linguistic characteristics used to differentiate registers (see Table 1) coincide with those used to differentiate other communicative parameters, such as the text's mode, genre or given style (e.g. the use of $I$ and you is a characteristic of spoken interaction and is also distinctive in the genre of email writing). Therefore, when trying to identify and use registers a useful guiding principle comes from the notion of proportion: the type of register will not be ultimately determined by the type of linguistic features but by their proportion and combination according to the roles performed by the participants in a specific context. In the process of these combinations one or two of the main registers act as pole/s of reference for the text/discourse (i.e. professional register), but also other subsidiary registers (i.e. social register and amicable register) are often included. In the case of commercial correspondence, the main professional roles are those standardized in usual business organization and communication. Section 4 includes specifications about the professional roles of the email writers who have participated in the corpus used for our study.

\section{PARAMETERS OF VARIATION IN ELECTRONIC CORRESPONDENCE}

As previous studies on email writing have already indicated, the genre of electronic correspondence has its own discourse peculiarities regarding the text's purpose, structure and writing process (i.e. Baron, 2000; Crystal, 2001). Regarding RV, some of these early studies also emphasized the importance of what they tend to call stylistic register (Gains, 1999; Giménez, 2000). These works do not present a clear definition of register and they express this concept mixed with others (mainly with style); however, they provide a series of key features that influence RV in this genre. In general terms, previous studies on register 
fluctuation in email writing concentrate on the following elements, which can be closely related to our approach:

(a) Headings: when senders relax, and adopt a more social or friendly attitude, they tend to use the headings with more promotional and phatic purposes or they spend less time in their elaboration (making the opening line of the message coincide with the subject header).

(b) Openings/Greetings: the salutation might oscillate from the conventional formula in formal letters (Dear Mr. or Ms. + recipient's surname) to very casual options which include no greeting, just the recipient's name or other more informal and unconventional ways of addressing the recipient, such as "Hi folks" or "Hello" (Gains, 1999: 85). The use of these friendly or more relaxed formula, both in greetings and farewells, is a frequent technique used in professional email writing to express closeness, complicity and ease the relationship (Waldvogel, 2007).

(c) Functions: email writing, both formal and casual, cover most of the standard functions of traditional business correspondence, becoming requestive, informative and directive emails the most frequent, according to Gains (1999) and Giménez (2000). Within these functions some emails initiate and others respond (e.g. some emails are informative/initiate and others informative/respond), but these functions seem to be expressed by using all the different levels of variation. Concerning register differentiation, these two authors already indicated that there is a noticeable increase of other functions implied which are not work- but socially-related, the aim being to maintain contact, to "chat" and "to praise or scold, and occasionally to have fun" (Gains, 1999: 99). The social and amicable roles of the writers are linguistically marked by the use of imperative and direct language, colloquial vocabulary, existential there and non-attribution of agency; amongst other features. Also, as Bosch Abarca (2010: 117) suggests, there are other two key functions which have a great influence in the emails' tone fluctuation: the sender's intention to persuade and to demonstrate politeness. Although politeness can be demonstrated on both formal and casual levels of the professional register, the brief and self-oriented nature of email writing obliges politeness indicators to be reduced or omitted (Baron, 2001; Bunz \& Cambell, 2004). This lack of politeness cues reduces the email's aim to a mere transmission of information rather than a means to establish a social relationship, neutralizing the tone of communication (Murphy \& Levy, 2006: 2).

(d) Medium: as Danet (1996), Giménez, (2000) and Yus (2010) have pointed out email correspondence - halfway between the letter and the telephone conversation - is the pioneer of popular written conversations used in Internet chats and social networks. 
Emails operate on a multimodal medium: written, oral and also pictorial (e.g. using emoticons and other visual techniques (Yus, 2010: 253). Since the main purpose of this medium is to save time and reduce work pressure, the more it fluctuates towards its spontaneous, unplanned and conversational side, the more informal features it incorporates: (1) unconventional use of punctuation, capitalization and spelling, (2) frequent repetition, (3) low conceptual density (with cleft-structures and use of existential there), (4) short or fragmented utterances/sentences, (5) coordination rather than subordination, (6) simple syntactic structures, (7) adjacency pairs, (8) rhetorical or phatic questions, (9) elliptical and contracted forms, both conventional and unconventional abbreviations, (10) idiosyncratic and colloquial word selection (e.g. "hi folks") and (11) reliance of the immediate context with frequent use of reference propositions and demonstrative modifiers. As Gains (1999: 96) indicates, in email writing there is also a special awareness of the limits and subtleties of the medium. Therefore, when communicating with a certain degree of complicity, users tend to use rhetorical devices such as humour or irony to cope with problems which hinder the effective use of the medium "as a means of mitigating discomfort" (op.cit, 97). Informal, casual and more unconventional versions of this multimodal genre allow writers to constantly include new features and uses that help them communicate more quickly and effectively (e.g. without forgetting any detail). For example, the increased use of embedded email responses in professional exchanges which emphasises the oral and conversational nature of this mode of communication, and consequently its more spontaneous, unplanned and informal dimension (Giménez, 2006).

(e) Closing: as Gains states this is "a fairly open area for personal expression, depending on the degree of formality of the message" (op.cit., 91). In his corpus this variation included: sender's name only or no closing at all, (All the) best (wishes/regards), (Much) Love (and respect), Bye/Cheerio for now, Cheers and Thank(s) (you).

Despite all these elements of fluctuation in everyday commercial electronic correspondence, the experts agree that there seems to be a regular, consistent and neutral form of communication in the business world characterized by a semi-formal co-operative tone of expression which follows linguistic principles, both in grammar and punctuation, "allied to what may be called standard written English" (Gains, 1999: 97). However, as they also agree, this register is sometimes raised, becoming more formal and detached for certain purposes (e.g. to mark the difference in status or seniority between the interlocutors), and at other times, the register is lowered, becoming more informal and personal for other reasons (e.g. to persuade the recipient or to encourage him/her to do something). This fluctuation has made "the search of commonalities of stylistic register proved to be a problematic exercise, due to the extremely wide diversity of registers adopted by the writers" (op.cit., 92). The next 
sections will cast some light on this through the analysis of the registers used within a corpus of business emails.

\section{REGISTER ANALYSIS OF BUSINESS ELECTRONIC CORRESPONDENCE}

The data for this study comes from tracking, over two weeks, the email messages received in one of the inboxes of our main donor, a senior female London executive. There were a certain amount of emails from the inbox which were removed: principally spam, when the sender/recipient belonged to the donor's private life or when the main subject/purpose was outside the professional sphere. The corpus resulting from this tracking and selective process consists of 224 emails from 54 professional business senders (including our donor) who were all native English speakers. Their respective professional roles in relation to the donor are: suppliers, buyers, company directors, PR and marketing executives and assistants, members of the press, magazine editors, publishing partners and clients. The distinction between internal and external source (Giménez, 2000) did not seem to be an especially relevant parameter in this case since the participants in the corpus showed closeness and detachment indistinctively with internal and external colleagues, forming a discourse community with no space/geographic boundaries. 120 of those messages were single, bidirectional (they were sent and stored independently by the donor) and 104 were sequenced messages: they were sent and stored in a chain of two messages ( 7 sequences), three messages (4 sequences), four messages (6 sequences), five messages (7 sequences), six messages ( 2 sequences) or seven messages (1 sequence).

The analysis was carried out in several phases:

Each single message and chain of messages was transferred into a text unit and all the confidential information was codified (people and company names were converted into invented names or initials and compromising information was either deleted or substituted by invented correlations).

10 business professionals, including the donor, were invited to collaborate as informants throughout the corpus analysis. They were asked to label single messages according to the three main tones of variation within the professional register: formal, neutral or casual. While they were classifying the messages they were asked to point out the main features contained within each message that helped them to choose each label.

Once the corpus was organized into the three main areas, the informants were asked to carry out a further classification, principally concentrating on casual messages, to relate each message with the other three main daily life registers (social, amicable and intimate). The informants also provided a list of features which related each text to these registers.

Finally, the 27 sequences of chained messages were analysed by the informants providing labels for each of the messages contained within each sequence. 


\section{RESULTS AND DISCUSSION}

The reporting of the results is divided in two main sections depending on whether the messages were received and stored individually or in sequences. This division is also necessary because the linguistic detail of the analysis of both parts was different, the first part being more in-depth for the purposes of this study, as the results show.

\subsection{Single email messages}

The first result is that from the 120 single messages, 35 were labeled as professional formal (F), 23 as professional neutral $(\mathrm{N})$ and 62 as professional casual (C), a much greater predominance and internal variation was apparent in this last group. The comments provided by the informants as relevant in this differentiation are listed in the following sub-sections.

\subsubsection{Professional formal register}

The total of 35 messages $(29.1 \%$ of the total) categorized as such and with the following predominant characteristics:

(a) The openings and endings are formal and polite (e.g. the most recurrent endings are As ever, Kind/Best regards and (All the/very) best), but this also happens with the introductory sentences (e.g. I hope you are well, instead of How are you? or How're you doing?).

(b) Most texts are quite dry and the main functions are informative, requests and invitations. The tone rises considerably when money/payments and position are included in the same text. Message number 13 of our corpus informs the head of a department about the company's budget, and although there are other messages between these interlocutors which are expressed in a more social tone, this one starts by saying "Further to your email of earlier please find the initial proposal as requested for inclusion in your OCM budget", and the ending: "I will keep you informed as to my progress".

(c) There is a careful use of paragraph structure so that readers can perceive that the writer has spent time ensuring that everything is correct, although sometimes senders relax their punctuation (e.g. they miss inverted commas when quoting a text).

(d) There is a frequent appearance of modality to show professionalism and politeness; essentially by using modal verbs (e.g. "we would be delighted to be informed") and emphasisers (e.g. "I very much look forward to meeting you both" or "Thank you so much for taking time").

(e) The writers use very traditional format, formula and vocabulary to express themselves. For example, when declining an invitation, the language used is:

(f) [Name+surname] thanks [name+surname] very much for his kind invitation to the 150th Anniversary Gala Dinner \& Party, but regrets that he has a speaking 
engagement that night in London, so is unable to attend. As one of the informants suggested, a more neutral version would be:

(g) Thank you for your kind invitation to attend the tasting on the [date] unfortunately I am unable to be there as I have a previous engagement.

(h) Although professional formal messages tend to be consistent in their tone, writers seem to be inclined to use more relaxed registers towards the end of the message (see example in Appendix A).

(i) The use of traditional formulas and ritual or ceremonial language is becoming a generational and educational issue since only writers of a certain age and education would use this format nowadays. Nevertheless this formal professional register is still frequent in daily business interaction, as the $30 \%$ of the emails contained in our corpus show. However, this might decrease during the next decade since young email writers, now used to communicating through chats and other social network media, are finding formal even colloquial expressions so far prototypical of casual email communication (Yus, 2010: 252).

\subsubsection{Professional neutral register}

The corpus contains a total of 23 neutral business emails (19.1\% of the total), with the following features:

(a) The function which predominates is informative providing a relatively large amount of data, even when it is the sender who solicits the information.

(b) There is a tendency to use shorter sentences, bullet points and headings rather than more florid formal English or personalized casual methods.

(c) Direct questions appear in the texts, as well as other conversational cues, but are expressed in formal language (i.e. using modality, mitigation and hedging); for example: "You know I sadly will not be in the UK in that date, will both you and C cover the stand or what do you propose?" or "Should we start thinking about the next one?".

(d) Writers spend time over explanations but carefully avoid colloquialisms, abbreviations or slang to make their language more objective and neutral.

(e) Senders also avoid opinions and subjective or emotive language. When they mention people they do not provide any personal comment and avoid acknowledging the position they might take on the subject.

(f) Writers tends to use this tone when they seem to be unable to gauge the recipient's response to their email or want to keep the possibility to move into a more or less formal style open; for example, email number 11 shows that the writer knows that an error has been made but does not know what the reaction would be ("Would it be possible to run something for them to help them?"), and in email 3 the writer does not know the reason why the information he has solicited has not been received yet, 
therefore he is awaiting a reply in order to see where he can position himself (either in a more formal tone, if the reason is not convincing, or a more casual relationship, if everything is easily resolved).

This register appears to be used as a catalyst to balance the other two poles; for example, in situations where the interlocutors have a close working relationship (marked by casual, social and amicable phraseology), yet they have to maintain professionalism due to commercial pressures (made apparent by formal English). In these cases the neutral register predominates throughout the text, however it is dotted with other registers (e.g. "I am away from Thursday until next Tuesday, but if someone can send through those changes then I will pick them up and do a comprehensive quote on everything next week").

\subsubsection{Professional casual register}

This is the most frequent tenor within the professional register with a total of 62 messages (about a $50 \%$ of the total); with the following distinctive features:

(a) Very casual greetings and endings (e.g. Hi folks and (Many) thanks).

(b) Most conversational and colloquial strategies mentioned in section 3 of this article were used in the texts; particularly the first and last sentences (e.g. "I'll get back to you as soon as I can").

(c) Writers are quite relaxed in their syntax and punctuation (e.g. "perhaps we can see if $P$. is available to attend instead of you?").

(d) Abbreviated language in its shortest form: one of the messages just had one word (the name of a colleague) and email 54 says: "Can we discuss pls". The language is similar to that used in mobile phone text messages.

(e) Most emails are accompanied by humor and irony, explicit throughout the text or implicit using inferring language or with the use of [...]); for example, "As [first name] mentions, subject to change ..." (the punctuation implying that there are going to be many more changes).

(f) Writers use casual terminology (e.g. informal phrasal verbs and idioms); for example, "Really sorry not to have given you the heads up Paul" (instead of a more neutral version such as "I am very sorry not to have informed you about this"). They also introduce creative/idiolectal expressions (e.g. "he is a funny onion" or "it's all gone pear-shaped").

Finally, as introduced in section 2 of this study, one of the most regular and consistent features of this register level is the high rate of fluctuation with other professional and nonprofessional registers. For example, the register of message 11 was broadly classified by the informants as professional casual; however, they also highlighted other registers used within the message as the roles of the interlocutors and other contextual features changed throughout the course of the text (see full text in Appendix B). 


\subsubsection{Other registers in business email writing}

According to the informants, from the 62 casual messages, only 8 were considered purely casual, the rest of them had features from other frequencies within the professional register or from other registers, mainly the social and the amicable ones, as table 2 shows.

\begin{tabular}{|l|l|}
\hline Differentiated registers within casual emails & $\mathrm{N}^{\circ}$ of emails \\
\hline Formal and Neutral & 2 \\
\hline Formal and Social & 5 \\
\hline Formal, Social and Amicable & 2 \\
\hline Neutral & 6 \\
\hline Social & 6 \\
\hline Social and Amicable & 20 \\
\hline Amicable & 11 \\
\hline Amicable and Intimate & 2 \\
\hline
\end{tabular}

Table 2. Registers differentiated within casual email writing.

Subsequently, apart from some features from other versions of the professional register itself (formal and neutral), the informants distinguished features from social encounters in 33 messages and features from amicable exchanges in 35 messages. Only two emails showed intimate features. Out of all of them, the most relevant and recurrent were the following:

\subsection{4.a. Social Register}

(a) Greeting and closing sections include: Hi Both, See you soon and Cheers ...; together with some other versions closer to amicable levels such as $\mathrm{Hi}$ all and Thank yoooooou!

(b) Senders include personal information about themselves and other colleagues, although expressed with a detached neutral attitude (e.g. But she is pregnant and I'm not sure when she's due)

(c) Senders also use subjective/emotive expressions and punctuation which gives a light hearted tone to the language (e.g. everything that we discussed from the meeting (I think!)).

(d) Most social issues are related to health, holidays, sports and leisure activities (e.g. Hope you enjoyed the Easter break)

(e) Social register often appears before or after some professional formal/neutral fragments to keep face and ease relationships (mainly in complaints and apologies); for example, after admitting fault, a sender says: Apologies, hopefully the English team are more organized than we have been in recent weeks!! and ends with All the best,. Another typical example is: I'm well thanks, just back from a week off, so apologies for ....

(f) Writers show this social attitude also by being chatty and gossipy. The following examples illustrate this conversational and opinionated attitude: By the way, ... Thought a bit odd, but apparently he is leaving. Bit of a surprise as we did that tasting 
with him only last Wed. Great shame I think for GB., Would Barry be okay to present? He must be worn out, he's just finished a huge project on ....

(g) A repeated mechanism in invitations seems to be to introduce the message with the standard formal invitation and then change into a more social even amicable tone when that invitation is personalized in the second part of the message.

(h) This social register also seems to concentrate in the PS section of the emails (e.g. PS: we missed our lunch slot. Do let me know when you're around again.).

At this casual level, the movement between registers (and consequently roles/intentions), even in short messages, is very frequent and meaningful; for example, email number 54 starts: Hi Rosie, hope you're well, I've a raging cold! (social register), then, the sender moves into professional casual/neutral register when asking for participation in a seminar going (I'm organizing the ...), changing into professional formal tone when formulating the actual invitation (we would like to invite you to join the seminar as a guest speaker ...), and finally, ending with an amicable register (we'll prepare a list of topics to discuss, so you won't be cast adrift!).

\subsection{4.b. Amicable Register}

(a) Greetings, closings and opening and ending sentences are those regularly used with friends; for example, Hi lovely, Where $r$ u ???, How's things?, Are we every going to meet again! or Thanks so much!; some of them even reaching a quite intimate tone (e.g. ending with Love or $x x$ ). Very frequently salutation and opening sentence are written together; for example, Hi all, hope everyone is well!, Hi there, I keep wondering how everything is? or Hi guys, hope you had a good BH [meaning bank holiday].

(b) Writers use this register to provide compromising information showing complicity or confidentiality (e.g. I'll find him someone great! meaning I will try to find him a good agency). They usually imply common previous history and the reference to people in codified complicity (e.g. Do you want to forget Ms Right given it's twice she has let us down? Or shall we go for third time lucky).

(c) This register is also marked by implicit and spontaneous emotions with subjective expressions and particular use of punctuation most times due to the speed of the communication (e.g. DH, 'Wish List' $h$ /w at last - Speak later, BC).

(d) There is a frequent use of peculiar terminology and abbreviations; for example, There's still a few TBD's in there which we've discussed (TBD meaning "to be done").

(e) Senders provide intimate (personal and family) information in a confidential tone (e.g. Paul's off to Ireland weekend after this. Is your mum feeling better?; this colleague ends with Would love to hear your news, followed by Love)

(f) Through this register senders find it easier to admit weaknesses (e.g. We might have a chance of getting all three, although its lottery odds!), to apologise (Sorry, it's been a hell of a week, and it's only Wednesday!) to prepare the ground for rejection (e.g. It isn't really what we had in mind for ...) and to keep face after some fault. For 
example, Hello babe!! is the salutation of a quite professional neutral message sent by a colleague who has not replied any messages for a long time and who also shows how busy still is dropping every now and then diverse shortenings (e.g. shld instead of should) together with other amicable cues such as he is always good value.

(g) This register is also used as a strategy to show or gain approval (e.g. I think this is reading to go, please comment. I've gone a bit blind to it! I will flag this up in their mail! or You are a star Barry sounds perfect ... I shall contact him directly., praising the other and thanking, expressing gratitude making the other feel good).

The way friendship, confidentiality and complicity is expressed by using RV, although very frequent, can be very subtle and complex in business emails: for example in an two email sequence, the sender says: "Strictly between you and I, [followed by casual statement] ... and no nepotism!" and then the message moves into more social grounds with "Hope you had a good session on Friday" (as a balancing effect to show politeness). The use of these registers encourages the reader to reply using the same level of complicity marked in expressions such as "Couldn't agree more!" or "Anyhow Friday was good though 2 bottles of sherry on an emptyish [sic] stomach is not that clever!").

\subsection{Sequenced email messages}

As mentioned in the previous section the number of sequenced messages analysed is 104 arranged in 27 chains of 2 messages (7), 3 messages (4), 4 messages (6), 5 messages (7), 6 messages (2) and 7 messages (1). According to the majority of the informants, the sequenced messages were labeled as follows (each register is codified using its initial distinctive letter: F/N/C within the professional register and S/A/I for the other three main registers):

(a) Chains of 2 messages:

\begin{tabular}{|l|l|l|l|}
\hline Type & Initiator & Reply & Occurrences \\
\hline 2.1 & $\mathrm{~F} / \mathrm{N}$ & $\mathrm{N} / \mathrm{C}$ & 4 \\
\hline 2.2 & $\mathrm{C} / \mathrm{A}$ & $\mathrm{N}$ & 1 \\
\hline 2.3 & $\mathrm{C} / \mathrm{A}$ & $\mathrm{C} / \mathrm{S}$ & 1 \\
\hline 2.4 & $\mathrm{C} / \mathrm{A}$ & $\mathrm{C} / \mathrm{A}$ & 1 \\
\hline
\end{tabular}

(b) Chains of 3 messages:

\begin{tabular}{|l|l|l|l|l|}
\hline Type & Initiator & Reply 1 & Close & Occurrences \\
\hline 3.1 & $\mathrm{~F}$ & $\mathrm{~N}$ & $\mathrm{C} / \mathrm{S}$ & 2 \\
\hline 3.2 & $\mathrm{~F}$ & $\mathrm{C} / \mathrm{S}$ & $\mathrm{C} / \mathrm{N}$ & 1 \\
\hline 3.3 & $\mathrm{~F}$ & $\mathrm{C} / \mathrm{A}$ & $\mathrm{A}$ & 1 \\
\hline
\end{tabular}


(c) Chains of 4 messages:

\begin{tabular}{|l|l|l|l|l|l|}
\hline Type & Initiator & Reply 1 & Reply 2 & Close & Occurrences \\
\hline 4.1 & F/N & N/C & A & N/C & 1 \\
\hline 4.2 & F & N & C/A & C/S & 1 \\
\hline 4.3 & F/N & N/A & N & S/A & 1 \\
\hline 4.4 & F & F & C/A & C/S & 1 \\
\hline 4.5 & N/C & C/A & N/C & C/A & 1 \\
\hline 4.6 & N/C & A & A & A & 1 \\
\hline
\end{tabular}

(d) Chains of 5 messages:

\begin{tabular}{|l|l|l|l|l|l|l|}
\hline Type & Initiator & Reply 1 & Reply 2 & Reply 3 & Close & Occurrences \\
\hline 5.1 & $\mathrm{~F}$ & $\mathrm{~N}$ & $\mathrm{C}$ & $\mathrm{A}$ & $\mathrm{A}$ & 3 \\
\hline 5.2 & $\mathrm{~F}$ & $\mathrm{C}$ & $\mathrm{A}$ & $\mathrm{A}$ & $\mathrm{A}$ & 2 \\
\hline 5.3 & $\mathrm{~N} / \mathrm{C}$ & $\mathrm{N} / \mathrm{C}$ & $\mathrm{A}$ & $\mathrm{A}$ & $\mathrm{A}$ & 1 \\
\hline 4 & $\mathrm{C}$ & $\mathrm{C}$ & $\mathrm{C}$ & $\mathrm{A}$ & $\mathrm{A}$ & 1 \\
\hline
\end{tabular}

(e) Chains of 6 messages:

\begin{tabular}{|l|l|l|l|l|l|l|l|}
\hline Type & Initiator & Reply 1 & Reply 2 & Reply 3 & Reply 4 & Close & Occurrences \\
\hline 6.1 & F & C & C & F & C & C & 1 \\
\hline 6.2 & F & N & N & S & S & A & 1 \\
\hline
\end{tabular}

(f) Chain of 7 messages ("Reply" is codified as "R"):

\begin{tabular}{|l|l|l|l|l|l|l|l|l|}
\hline Type & Initiator & R. 1 & R. 2 & R. 3 & R. 4 & R. 5 & Close & Occurrences \\
\hline 7.1 & F & C & N & A & S & A & A & 1 \\
\hline
\end{tabular}

These findings show that the most usual sequence is not just only the most predictable one: Initiator + Reply ( 7 sequences found), not even the sequence Initiator + Reply + Confirmation (4 sequences of 3 messages), but the sequence of 5 messages ( 7 instances) with a meaningful number of 4 message chains (6 sequences). This indicates that when writers establish an email interaction the tendency is to expect the sequence to have more than just a reply and a confirmation. However, the most significant finding is the general progressive relaxation of the interaction along the flow of messages: 20 sequences start by a first email (initiator) where the predominant register is professional formal, whereas the last message (close) ends up with more predominant social (in 5 messages) and friendly features (in 14 sequences), with the amicable register becoming the most regular when the interlocutors complete their exchange of information. Further analysis is currently being carried out on this section for a forthcoming publication. 


\section{CONCLUSION}

The genre of emails was not included in published textbooks and course materials until the late 90s. Today, most business English manuals include activities to practise email writing and also to raise RV awareness. There are even some very useful guides (i.e. Shypley \& Schwalbe, 2008) and teaching manuals on the market (i.e. Emmerson, 2004), mainly dedicated to professional electronic correspondence. However, in most of them, the concept of register still appears diffuse in relation to other language varieties and, although they distinguish certain levels of variation (mainly formal, standard and informal), these three levels do not refer to the register modulation of just one communicative context in everyday interaction (e.g. professional contexts) but to the whole span of RV coverage in current human communication. This is why we consider it essential for improving professional and personal communication studies which provide new methods (easy and accessible to nonlinguists) to systematically approach this type of variation.

With this purpose, this paper offers a typology which aims to be helpful in the differentiation of RV. It also reviews and adapts to this approach the most relevant features provided by experts in the field and finally highlights new parameters to detect and use professional formal, neutral and casual communication in current business emails, together with social and amicable language features which as reflected in the results are increasingly present in this versatile and dynamic genre.

As the study shows, today's business email writers, depending on their intentions, feelings and interests, frequently use RV as a strategy or tool to facilitate communication and improve the relationship with their colleagues, adopting roles which are more similar to those used with acquaintances and friends more than with working companions. Therefore, to a certain extent, the mastering of electronic business correspondence is dependent on the user's capacity to identify and use these register's distinguishing features.

Although research provides a wide range of lexical, idiomatic, functional, grammatical and textual distinctive parameters, there are still many aspects of RV in business email writing which have not been covered and might be equally useful; for example, the influence of attachments and additional information enclosed in the identification of registers (some professional neutral emails paradoxically attach jokes and video clips). Another further area of study is how the concept of appropriateness, convention or standard is progressively becoming misleading within this genre: unconventional abbreviations are progressively becoming more conventional (Giménez, 2000: 243) and spontaneous conversational features are progressively becoming the norm for those users familiarized with new social media networks (Yus, 2010: 252). 


\section{ACKNOWLEDGEMENTS}

I would like to express my gratitude to the email donor who generously provided the corpus for this study and also to the informants who have collaborated with the corpus analysis.

\section{REFERENCES}

Alcaraz Varó, E. (2007). La sociedad del conocimiento, marco de las lenguas profesionales y académicas. In E. Alcaraz Varó, J. Mateo Martínez \& F. Yus Ramos (eds). Las Lenguas Profesionales y Académicas (pp. 3-12). Barcelona: Ariel.

Baron, N. (2000). Alphabet to Email. London: Routledge.

Biber, D. (1995). Dimensions of Register Variation. Cambridge: Cambridge University Press.

Bosch Abarca, E. (2010). English for general business purposes. In R. Giménez Moreno (Ed.) (pp. 99137).

Brunz, U. \& Campbell, S. W. (2004). Politeness Accommodation in Electronic Mail. Communication Research Reports 21(1), 11-25.

Crystal, D. (2002). Language and the Internet. Cambridge: Cambridge University Press.

Danet, B. (2001). Cyberplay: Communicating Online. Oxford: Berg.

Emmerson, P. (2004). Email English. Oxford: Macmillan Education.

Gains, J. (1999). Electronic Mail-A new style of communication or just a new medium? An investigation into the text features of e-mail. English for Specific Purposes 18, 81-101.

Ghadessy, M. (Ed.) (1988). Registers of Written English: Situational Factors and Linguistic Features. London: Pinter Publishers.

Giménez Moreno, R. (1997). The boundaries of the concepts of genre, register and style in academic discourse. In J. Piqué \& D. Viera (Eds.). Applied Languages: Theory and Practice in ESP (pp. 37-45). Valencia: Universitat de València.

Giménez Moreno, R. (2006). A new approach to register variation: the missing link. Ibérica, 12, 89110.

Giménez Moreno, R. (2010). English for higher education studies. In R. Giménez Moreno (Ed.) (pp. 295-334).

Giménez Moreno, R. (Ed.) (2010). Words for Working. Professional and Academic English for International Business and Economics. Valencia: PUV.

Giménez, J. C. (2000). Business e-mail communication: some emerging tendencies in register. English for Specific Purposes, 19, 237-251.

Giménez, J. C. (2006). Embedded business emails: meeting new demands in international business communication. English for Specific Purposes, 25, 154-172.

Gregory, M. \& Carroll, S. (1978). Language and Situation: Language Varieties and their Social Contexts. London: Routledge and Kegan Paul.

Halliday, M. A. K. (1978). Language and Social Semiotic. London: Edward Arnold.

Halliday, M. A. K. (1980). Register variation and identity of a text. Sophia Linguistica, 6, 60-79.

Hawisher, G. H. \& Moran, C. (1993). Electronic Mail and the Writing Instructor. College English, 55 (6), 627-643.

Murphy, M. \& Levy, M. (2006). Politeness in intercultural email communication. Journal of Intercultural Communication, 12, 1 -11.

Ruiz Garrido, M. F. (2010). Language variation in English for Business and Economics. In R. Giménez Moreno (Ed.) (pp. 57-96).

Shipley, D. \& Schwalbe, W. (2007). The Essential Guide to Email for Office and Home. New York: Knopf.

Waldvogel, J. (2007). Greetings and Closings in Workplace Email. Journal of Computer-Mediated Communication, 12 (2), 456-477.

Yus, F. (2010). Ciberpragmática 2.0. Barcelona: Ariel. 


\section{APPENDICES}

\section{APPENDIX A: Example of RV within a professional formal business email}

\section{Message 45 from the analysed corpus}

\section{Register Variation}

Context: This message is sent by the director of a PR company (Anne Anderson) who is a trade contact of the recipient (Janet Hutchinson), the director of a magazine. However, they have a long-standing professional relationship and have coincided socially on many occasions.

From: Anne Anderson

Sent: 22 February 2010 10:47

To: Janet Hutchinson

Subject: Independent CA Tasting

Dear Janet

Headings:

Professional Neutral

Text:

1. Professional Neutral

2. Professional Formal

Following the success last year of the UK's first ever independent $C A$ tasting, co-hosted by $B X$ and $R F$, please find below an invitation to the sequel-CA II on $26^{\text {th }}$ May 2010 at the Abbey Venue.

I am attaching a press release and if you need any more information, please let me know.

I hope you are well and to see you there.

Missed you on your last trip. Do let me know when you are over again and free for a wee jar.

Best,
3. Professional Neutral

4. Social

5. Amicable

6. Professional Neutral 
APPENDIX B: Example of RV within a professional casual business email

\section{Message 11 from the analysed corpus}

Context: This message is sent by a Sean Taylor (head of the web design team of a company) to his client Adam Brown, who is the son of Christopher Brown (the owner of Adam's company), copying in both, Christopher and Alexander Butler (a member of Sean's design team).

RE: Competitors

From: Sean Taylor

Sent: 23 February 2010 15:47

To: Adam Brown

Cc: Alexander Butler; Christopher Brown

Subject: Re: Competitors

Hi Adam - thanks for that list, very useful.

Alex - will you be able to go through these from a design perspective?

Adam, you were going to come up with some answers to the TBDs we wrote down in the meeting for today - is that still possible? This is the list as far as $i$ have it:

1. What's the minimum bottles or 6-bottle cases for mixed wine?

2. How do prices change based on picking costs?

3. News registrants get what kind of offer if they order within 30 days?

4. Referral offers

I will be reworking the document on Tuesday and then re-quoting on it all and sending that through to you Christopher on Thursday at the latest.

Cheers - have a great weekend....

Sean

\section{Register Variation}

Headings:

Professional Neutral

Text:

1. Amicable

2. Professional Casual

3. Professional Neutral

4. Professional Formal

5. Amicable-Social 